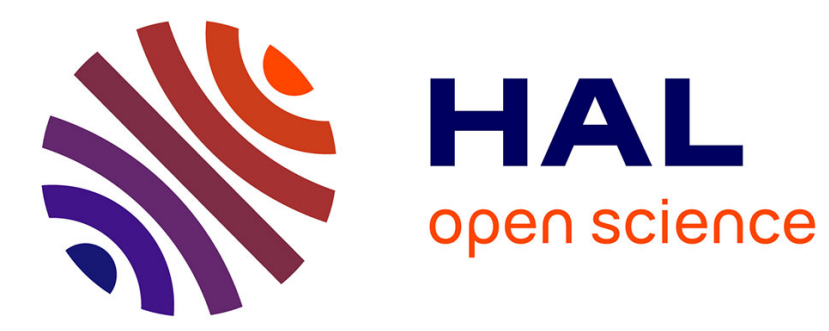

\title{
SEXAFS Study of the GaAs/InP Interface
}

\author{
M. Proietti, S. Turchini, F. Martelli, J. Garcia, T. Prosperi, D. Chandesris, J.
}

Vogel

\section{To cite this version:}

M. Proietti, S. Turchini, F. Martelli, J. Garcia, T. Prosperi, et al.. SEXAFS Study of the GaAs/InP Interface. Journal de Physique IV Proceedings, 1997, 7 (C2), pp.C2-697-C2-698. 10.1051/jp4:1997208 . jpa-00255154

\section{HAL Id: jpa-00255154 https://hal.science/jpa-00255154}

Submitted on 1 Jan 1997

HAL is a multi-disciplinary open access archive for the deposit and dissemination of scientific research documents, whether they are published or not. The documents may come from teaching and research institutions in France or abroad, or from public or private research centers.
L'archive ouverte pluridisciplinaire HAL, est destinée au dépôt et à la diffusion de documents scientifiques de niveau recherche, publiés ou non, émanant des établissements d'enseignement et de recherche français ou étrangers, des laboratoires publics ou privés. 


\title{
SEXAFS Study of the GaAs/InP Interface
}

\author{
M.G. Proietti, S. Turchini*, F. Martelli**, J. Garcia, T. Prosperi*, D. Chandesris*** and J. Vogel*** \\ ICMA-CSIC, Universidad de Zaragoza, Facultad de Ciencias, Plaza S. Francisco s.n., 50009 Zaragoza, \\ Spain \\ * ICMAT-CNR, cp. 10,00016 Monterotondo Stazione, Italy \\ ** Fondazione Ugo Bordoni, via B. Castiglione 59, 00142 Roma, Italy \\ *** LURE, bâtiment 209D, 91405 Orsay, France
}

\begin{abstract}
Extended X-Ray Absorption Fine Structure measurements have been performed at the Ga and As K-edge of a nominal 3 ML GaAs grown by Molecular Beam Epitaxy on a InP(100) substrate deoxidized in As atmosphere. We exploited the in-plane linear polarization of the synchrotron radiation measuring SEXAFS spectra taken with the polarization vector parallel and perpendicular to the growth direction. By comparing the ratio of the coordination numbers of the pairs As-Ga, As-In, Ga-As, taken at the two different angles of the polarization vector, a quantitative model of the interface is obtained. Two well defined layers form on the InP substrate giving rise to the following sample structure: $3 \mathrm{ML}$ GaAs/3 ML InAs/InP. This rules out the formation of InGaAs or InGaAsP layers at the interface.
\end{abstract}

\section{INTRODUCTION}

The understanding of the formation process of the interfaces is worth for the control of the quality of heterostructures as quantum wells and superlattices. In lattice mismatched materials in pseudomorphic growth regime, where the tetragonal distortion causes an increasing of the elastic energy, the role of the interface is important for the formation and propagation of defects, which lower the quality in terms of device performances $[1,2]$.

\section{EXPERIMENTAL}

The sample studied consists of a single heterointerface composed of $3 \mathrm{ML}$ of GaAs grown on InP(100) substrate by molecular beam epitaxy (MBE). The InP substrate was deoxidized under As4 flux before growing of the epitaxial layers. The growth temperature was chosen to be $420^{\circ} \mathrm{C}$ at the approximate rate of $0.5 \mathrm{ML} / \mathrm{s}$. The growth process was monitored in situ by means of reflected high energy electron diffraction (RHEED). In this way an As cap, easily removable by heating the samples, was deposited onto the epilayer to prevent the oxidation of the interface by air, when transferring the sample to the experimental chamber. The conditions of deposition of the As cap were: substrate temperature $-30^{\circ} \mathrm{C}$, As pressure $10^{-6}$ torr, exposure time 1 hour. The data were collected at beamline DW21A at DCI (LURE), using a double crystal Si(111) monochromator.

The absorption coefficient was measured by energy resolved fluorescence at the $K_{\alpha}$ of $\mathrm{Ga}$ and As. Fluorescence re-absorption was neglected because of the low thickness of the epilayer. The samples were decapped in situ by electron bombardment while checking the temperature with a pyrometer. The temperature was kept below $350^{\circ} \mathrm{C}$ in order to avoid the relaxation of the strained epilayer. The base pressure was as low as $10^{-10}$ torr. The absorption coefficient was measured in two geometry, with the polarization vector of the light parallel and perpendicular to the growth direction.
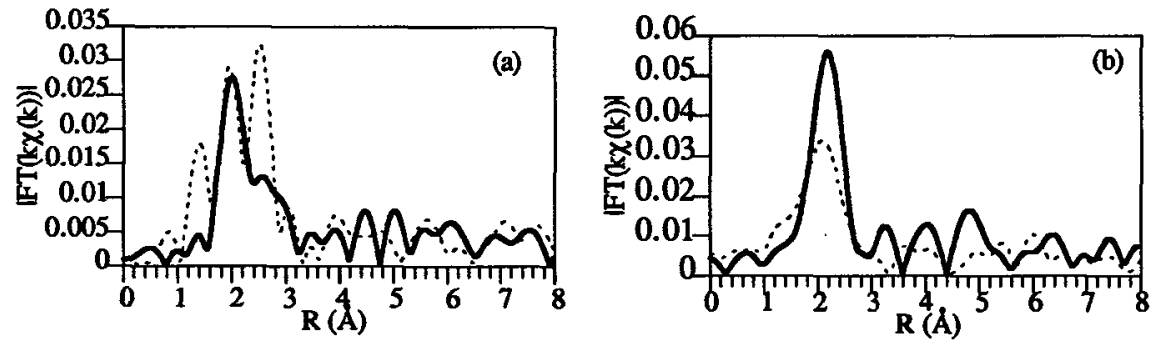

Figure 1: Fourier transform modules of the EXAFS spectra: a) As K-edge, b) Ga K-edge. The solid line represents the measure with the polarization vector perpendicular to the growth direction, the dashed one the measure with the polarization vector parallel to the growth direction.

\section{DATA ANALYSIS AND DISCUSSION}

The $\chi(k)$ signal was extracted by the raw data by means of the EXBACK program, the pre-edge was fitted with a polynomium, while for the extraction of EXAFS wiggles a polynomial spline of the third order was chosen. The Fourier transform of the $\mathrm{k} \chi(\mathrm{k})$ were performed in the range $2.5-12.0 \mathrm{~A}^{-1}$ by applying a Hanning window. Data were antitransformed to isolate the 
contribution of the first shell. The phases and the amplitudes were extracted from powder spectra of GaAs and InAs measured in transmission mode at the $\mathrm{Ga}$ and $\mathrm{As} \mathrm{K}$ edges respectively. In this work the in-plane orbit polarization vector of the beam was exploited, in fact the symmetry of the probe can be coupled with the symmetry of the sample. In the case of strained heterostructure the symmetry of the problem (tetragonal distortion in the epilayer) suggests to measure EXAFS with the polarization vector along and perpendicular the growth direction. The polarization vector is then oriented along the (100) and $(0-11)$ direction, the perpendicular direction chosen. The Fourier transform of the spectra are reported in figure 1 . The As Kedge shows in the first coordination shell two distances due to the As-Ga and As-In bonds, as reported in a previous study [3]. Comparing the intensities of the Fourier transform a strong anisotropy is found in the first shell of neighbors, that can be explained because the epilayer is very thin, then the SEXAFS signal weights the interface contribution. Moreover this clearly excludes the diffusion of In from the substrate to the epilayer to form an InGaAs randomly oriented alloy. The fit values of the first shell are reported in table I.
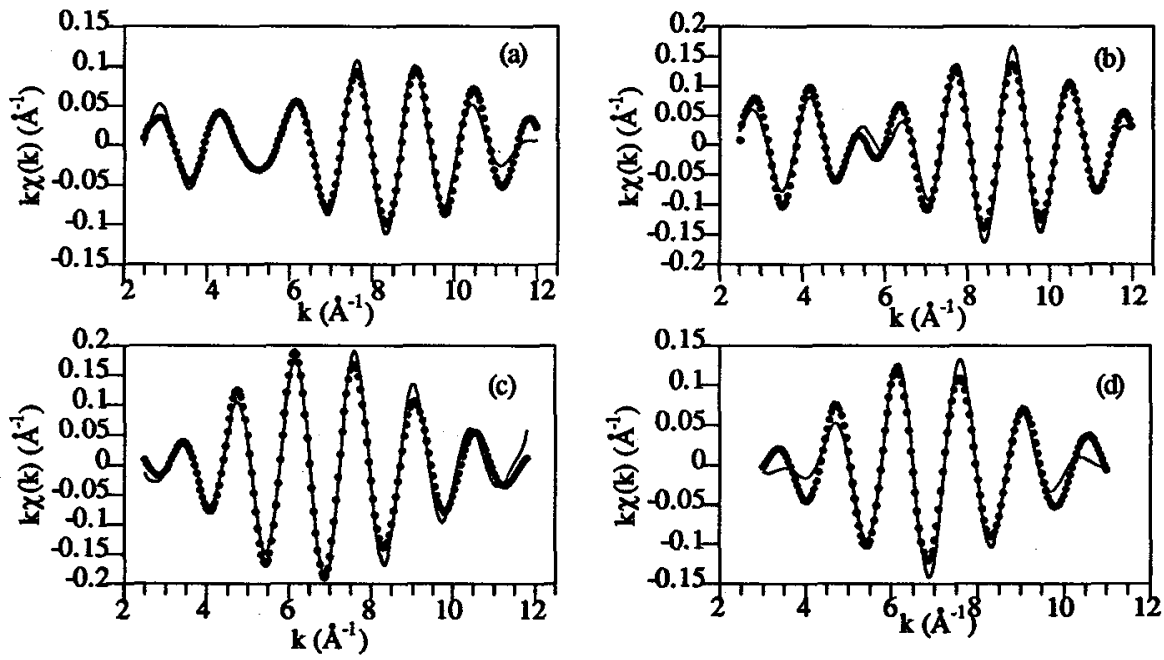

Figure 2: K-edge filtered Fourier spectra (solid line) with relative fit (mark points): a) As with polarization vector perpendicular to the growth direction, b) As with the polarization vector parallel to the growth direction, c) Ga with polarization vector perpendicular to the growth direction, d) $G$ a with polarization vector parallel to the growth direction.

To discuss the data it is convenient to define as a representative parameter the ratio between the coordination number obtained in the different geometry of absorption:

$\mathrm{r}=\mathrm{N}(\boldsymbol{\varepsilon} \|) / \mathrm{N}(\varepsilon \perp)$

where $\varepsilon$ is the polarization vector.

In table II the calculation of the $\mathrm{r}$ parameter for the following simple models of the interface is reported: a) $3 \mathrm{ML}$ GaAs/inP with sharp interface, b) $3 \mathrm{ML}$ GaAs/3 ML InAs/InP, c) $6 \mathrm{ML}$ InGaAs/InP with an In gradient toward the surface.

Table 1

Table 2

$\begin{array}{lllll}\text { EXAFS } & \text { atom } & \text { coord. } & R(\AA) & \Delta \sigma^{2}\left(\AA^{2}\right) \\ \text { Kairs } & \text { number } & & \\ \text { K Ga } \varepsilon \| l & \text { Ga-As } & 3.5 & 2.45 & 0.004 \\ \text { Ka } \varepsilon \perp & \text { Ga-As } & 4.2 & 2.45 & 0.002 \\ \text { K As } \text { Ell } & \text { As-Ga } & 1.6 & 2.46 & 0.000 \\ & \text { As-In } & 2.3 & 2.62 & 0.000 \\ \text { K As } \perp \perp & \text { As-Ga } & 1.7 & 2.47 & 0.000 \\ & \text { As-In } & 1.0 & 2.62 & 0.000\end{array}$

$\begin{array}{lllll}\text { model } & \text { rGa-As } & \text { rAs-Ga } & \text { rAs-In } & \text { rtot } \\ \text { a } & 1.23 & 1.25 & - & - \\ \text { b } & 1.08 & 1.0 & 2.0 & 1.25 \\ \text { c } & 1.24 & 1.6 & 1.0 & 1.25 \\ \text { exp } & 0.8 & 0.9 & 2.3 & 1.4\end{array}$

The experimental data are close to the $3 \mathrm{ML}$ GaAs/3 ML InAs/InP. The presence of a strained InAs which acts as substrate for the GaAs tensile epitaxial growth is an interesting result that points out the complexity of the interface modeling even for highly controlled epitaxial systems. The deoxidization of the InP surface in an As atmosphere with the complete substitution of $P$ with As seems to be the possible mechanism of interface formation of the samples studied.

References

[1] See for example T.R. Chen, Y.H. Zhuang, and L.E. Eng, Appl. Phys. Lett. 57, 2402 (1990)

[2] "Strained Layer Superlattices Physics", ed. T. Pearsall, Ac. Press, N.Y. (1990)

[3] M.G. Proietti, S.Turchini,F.Martelli, J. Garcia and T. Prosperi, J. Appl. Phys. 77, 62 (1995) 